\title{
Clinical Importance of Koch's Triangle Size in Children A Study Using 3-Dimensional Electroanatomical Mapping
}

\author{
Naokata Sumitomo, MD; Shigeru Tateno, MD*; Yoshihide Nakamura, MD**; \\ Hiroya Ushinohama, MD`; Kazuo Taniguchi, MD; Rie Ichikawa, MD; \\ Junji Fukuhara, MD; Osamu Abe, MD; Michio Miyashita, MD; \\ Hiroshi Kanamaru, MD; Mamoru Ayusawa, MD; \\ Kensuke Harada, MD; Hideo Mugishima, MD
}

\begin{abstract}
Background Catheter ablation inside the Koch's triangle has a risk for complete atrioventricular block.
Methods and Results The anatomic size of the coronary sinus (CS) and His bundle (HB) in children and the distance between them was studied using a 3-dimensional electroanatomical mapping system (CARTO). Fiftythree children (mean age, 11.8 \pm 3.7 years) without congenital heart disease (ie, 24 with atrioventricular re-entrant tachycardia, 18 with atrioventricular nodal re-entrant tachycardia, 7 with atrial tachycardia, 2 with ventricular tachycardia and 2 with atrial flutter) were studied. The size of the HB recording area was $148 \pm 97 \mathrm{~mm}^{2}$ and the size of the CS was $66 \pm 44 \mathrm{~mm}^{2}$. The size of the CS and the distance between the HB and CS $(18 \pm 7 \mathrm{~mm})$ were proportional to body weight, body length and body surface area. All patients underwent catheter ablation, including 25 ablations inside Koch's triangle. Catheter ablation was successful in 52 patients without any atrioventricular nodal injury.

Conclusions The CS size and the distance between the HB and CS increased proportionally with children's growth. To know the distance from the HB to the ablation point is useful in avoiding atrioventricular node injury, and information about the length of Koch's triangle may provide supportive information when applying radiofrequency energy inside Koch's triangle without needing to use the CARTO system in children, but this merits further investigation. (Circ J 2007; 71: 1918-1921)
\end{abstract}

Key Words: Atrioventricular node; Catheter ablation; 3-Dimensional electroanatomical mapping system (CARTO); Koch's triangle

$\mathbf{T}$ he atrioventricular node is situated at the apex of the triangle of Koch, which is formed by the tricuspid valve annulus, the ostium of the coronary sinus (CS) and the tendon of Todaro. Atrioventricular nodal re-entrant tachycardia and the common form of atrial flutter (AFL) have critical slow conduction through a re-entry circuit inside the triangle of Koch. In addition, the right mid or posterior septal accessory pathways (APs), atrial tachycardia (AT) around CS, and junctional tachycardia may use a re-entrant circuit or originate from a focus within Koch's triangle. Catheter ablation of these arrhythmias is associated with the potential risk of atrioventricular nodal injury and block. In adults, there is no relationship between the body surface area (BSA) and the dimensions of the triangle of Koch? In contrast, in the pediatric population the dimensions of Koch's triangle are best predicted by the $\mathrm{BSA}^{3}$ or age 4

(Received April 26, 2007; revised manuscript received August 13, 2007; accepted August 24, 2007)

Department of Pediatrics, Nihon University School of Medicine, Tokyo, *Department of Pediatrics, Chiba Cardiovascular Center, Chiba, **Second Department of Pediatrics, Wakayama Red Cross Hospital, Wakayama and 'Department of Cardiology, Fukuoka Children's Hospital, Fukuoka, Japan

Mailing address: Naokata Sumitomo, MD, Department of Pediatrics, Nihon University School of Medicine, 30-1 Oyaguchi Kamimachi, Itabashi-ku, Tokyo 173-8610, Japan. E-mail: naokata@med.nihon-u. ac.jp
These prior studies were performed by analyzing autopsy specimens or during surgery; however, the dimensions may differ in the beating heart during catheterization. The present study was performed to determine the dimensions of the triangle of Koch in children by electroanatomical mapping.

\section{Methods}

From July 2005 to August 2006, consecutive patients aged younger than 20 years who were referred to our institutes for catheter ablation were studied. Organic heart disease was excluded by physical examination, chest radiography and echocardiogram. Fifty-three children (30 males, 23 females) with a mean age of $11.8 \pm 3.7$ years (range, 4-19 years) were included in the study. Their mean body weight (BW) was $41.6 \pm 14.2 \mathrm{~kg}$ (range, $17.9-71.6 \mathrm{~kg}$ ), mean body length (BL) was $147.1 \pm 18.3 \mathrm{~cm}$ (range, $109.4-178.0 \mathrm{~cm}$ ), and mean BSA was $1.30 \pm 0.30 \mathrm{~m}^{2}$ (range, $0.74-1.85 \mathrm{~m}^{2}$ ).

After written informed consent was obtained from the child's parent or guardian, electrophysiologic studies were performed under intravenous anesthesia. Anti-arrhythmic therapy was discontinued for at least 5 half-lives prior to ablation. Electrode catheters were introduced via the femoral, cervical or subclavian vein, and positioned in the right atrium, right ventricle, septal leaflet of the tricuspid valve, and CS.

The recording area of the His bundle (HB) potential and 

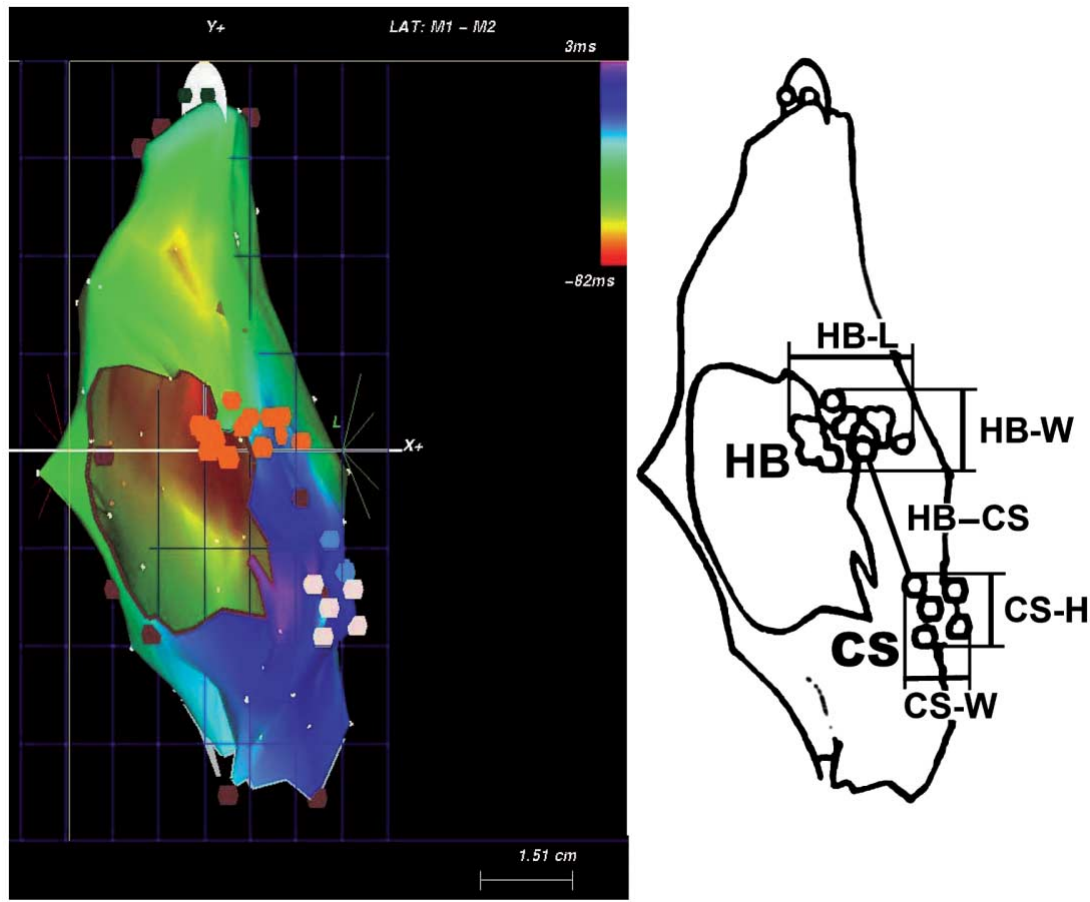

Fig 1. Electroanatomical mapping of the His bundle (HB) and coronary sinus (CS). The left panel shows a left anterior oblique view of a patient with atrial flutter. The orange dot marks the $\mathrm{HB}$ recording area, the white dot marks the ostium of the CS, and the blue dot marks the area of slow pathway. The right panel shows the measurement of HB and CS area. HB-L, length of $\mathrm{HB}$; HB-W, width of $\mathrm{HB}$; $\mathrm{CS}-\mathrm{H}$, vertical diameter of CS; CS-W, horizontal diameter of CS; HB-CS, distance between the HB and $\mathrm{CS}$.

Table 1 Measurement of Koch's Area

\begin{tabular}{|c|c|c|c|c|c|c|c|c|c|}
\hline & \multirow{2}{*}{ Mean $\pm S D$} & \multicolumn{2}{|c|}{ Age (years) } & \multicolumn{2}{|c|}{$B L(\mathrm{~cm})$} & \multicolumn{2}{|c|}{$B W(\mathrm{~kg})$} & \multicolumn{2}{|c|}{$B S A\left(m^{2}\right)$} \\
\hline & & $r^{2}$ & $p$ & $r^{2}$ & $p$ & $r^{2}$ & $p$ & $r^{2}$ & $p$ \\
\hline$H B-L(\mathrm{~mm})$ & $17.1 \pm 6.8$ & 0.051 & 0.10 & 0.059 & 0.08 & 0.030 & 0.22 & 0.044 & 0.13 \\
\hline$H B-W(m m)$ & $11.0 \pm 5.0$ & 0.000 & 0.96 & 0.001 & 0.86 & 0.001 & 0.81 & 0.000 & 0.95 \\
\hline$H B$ area $\left(\mathrm{mm}^{2}\right)$ & $147.9 \pm 97.0$ & 0.025 & 0.26 & 0.021 & 0.30 & 0.016 & 0.37 & 0.019 & 0.32 \\
\hline $\mathrm{CS}-\mathrm{H}(\mathrm{mm})$ & $9.5 \pm 3.3$ & 0.050 & 0.11 & 0.069 & 0.06 & 0.062 & 0.08 & 0.070 & 0.06 \\
\hline$C S-W(\mathrm{~mm})$ & $8.3 \pm 3.2$ & 0.021 & 0.30 & 0.081 & 0.04 & 0.053 & 0.10 & 0.067 & 0.06 \\
\hline CS area $\left(\mathrm{mm}^{2}\right)$ & $66.0 \pm 44.2$ & 0.044 & 0.13 & 0.096 & 0.03 & 0.079 & 0.04 & 0.091 & 0.03 \\
\hline$H B-C S(\mathrm{~mm})$ & $18.4 \pm 6.9$ & 0.127 & 0.01 & 0.086 & 0.03 & 0.138 & 0.01 & 0.118 & 0.01 \\
\hline$H B-S P(\mathrm{~mm})$ & $17.4 \pm 11.1$ & 0.177 & 0.03 & 0.109 & 0.09 & 0.152 & 0.04 & 0.137 & 0.05 \\
\hline
\end{tabular}

Values are reported as the mean $\pm S D$. Linear correlation values $\left(r^{2}\right)$ and $p$ values for age, $B L, B W$ and $B S A$ are shown. Note that the $C S$ area increases with $B L, B W$ and $B S A$. The $H B-C S$ increases with age, $B L, B W$ and $B S A$.

$B L$, body length; $B W$, body weight; $B S A$, body surface area; HB-L, length of His bundle; $H B-W$, width of His bundle; HB, His bundle; $C S-H$, vertical diameter of coronary sinus; $C S$-W, horizontal diameter of coronary sinus; $C S$, coronary sinus; $H B-C S$, distance between the $H B$ and $C S ; H B-S P$, distance between the $H B$ and slow pathway potential.

the ostium size of the CS were entirely mapped out using a NAVI-STAR catheter (Biosense Webster, CA, USA) and the 3-dimensional (D) geometry of Koch's triangle was determined. The length (HB-L) and width (HB-W) of the $\mathrm{HB}$, the vertical diameter $(\mathrm{CS}-\mathrm{H})$ and horizontal diameter (CS-W) of the CS, and the shortest distance between the lowest recording portion of the $\mathrm{HB}$ to the upper part of the $\mathrm{CS}(\mathrm{HB}-\mathrm{CS})$, and the shortest distance between the lowest recording portion of the $\mathrm{HB}$ to the upper part of the slow pathway potential $(\mathrm{HB}-\mathrm{SP})$ were measured within a 3-D electroanatomical mapping system (CARTO, BiosenseWebster; Fig 1). The sizes of the HB and CS were calculated using the equation for elliptical area:

\section{Size of $\mathrm{HB}=\mathrm{HB}-\mathrm{L} \times \mathrm{HB}-\mathrm{W} \times \pi / 4$ \\ Size of $\mathrm{CS}=\mathrm{CS}-\mathrm{W} \times \mathrm{CS}-\mathrm{H} \times \pi / 4$}

The CS catheter was used as the reference catheter for the 3-D electroanatomical mapping.

Using a standard burst and extrastimulus protocol in the right atrium and right ventricle, dual atrioventricular nodal pathways (defined as $>50 \mathrm{~ms}$ increase in the A2-H2 interval with a 10-ms decrement in the A1-A2 interval) were demonstrated in 26 patients, and sustained atrioventricular nodal tachycardia (AVNRT) was induced in 18 patients. The slow pathway5,6 AP7,8 AT, AFL, and ventricular tachycardia (VT) were ablated using standard ablation technique.

\section{Statistical Analysis}

Quantitative data from the studies are presented as the mean \pm SD and were analyzed statistically by Wilcoxon nonparametric analysis using JMP version 5.1 (SAS Institute Inc, Cary, NC, USA), with statistical significance defined as $p<0.05$. Linear regression analysis was used when appropriate.

\section{Results}

Result of Electrophysiologic Studies

Diagnostic electrophysiologic studies revealed 24 atrioventricular re-entrant tachycardias, 18 AVNRT, 7 AT, 2 VT, 
Table 2 Linear Correlation Formula for Each Measurement

\begin{aligned} \hline \hline CS area $\left(\mathrm{mm}^{2}\right) & =-44 \pm 0.8 \mathrm{BL}(\mathrm{cm}) \\ & =29 \pm 0.9 \mathrm{BW}(\mathrm{kg}) \\ & =8.5 \pm 44.5 \mathrm{BSA}\left(\mathrm{m}^{2}\right) \\ & =10.5 \pm 0.7$ age $($ years $) \\ & =2.1 \pm 0.1 \mathrm{BL}(\mathrm{cm}) \\ & =10.9 \pm 0.2 \mathrm{BW}(\mathrm{kg}) \\ & =8.3 \pm 7.8 \mathrm{BSA}\left(\mathrm{m}^{2}\right) \\ H B-S P$ distance $(\mathrm{mm}) & =-0.9 \pm 1.4 \mathrm{age}($ years $) \\ & =4.3 \pm 0.3 \mathrm{BW}(\mathrm{kg})\end{aligned}$

The linear correlation formula for each measurement to age, $B L, B W$ and $B S A$. Refer to Table 1 for abbreviations.

\section{CS area $\left(\mathrm{mm}^{2}\right)$}

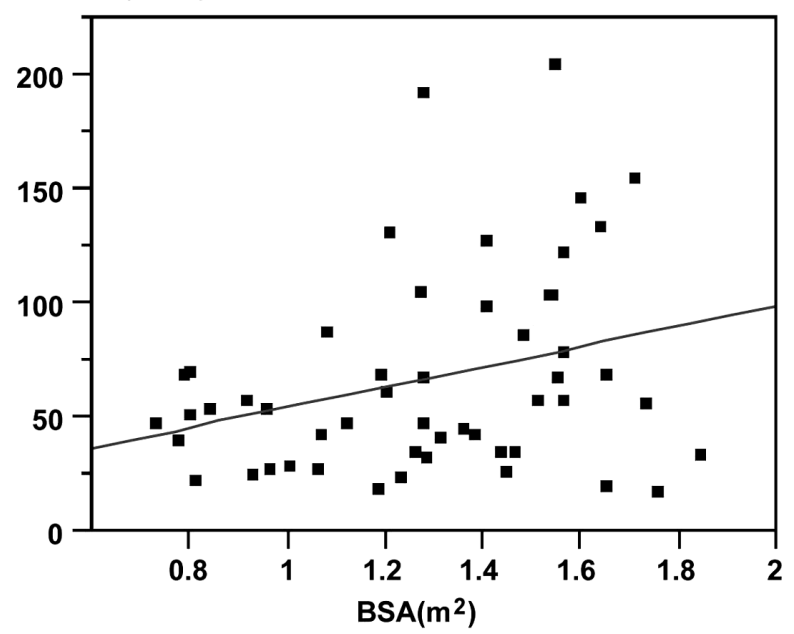

HB-CS distance $(\mathrm{mm})$

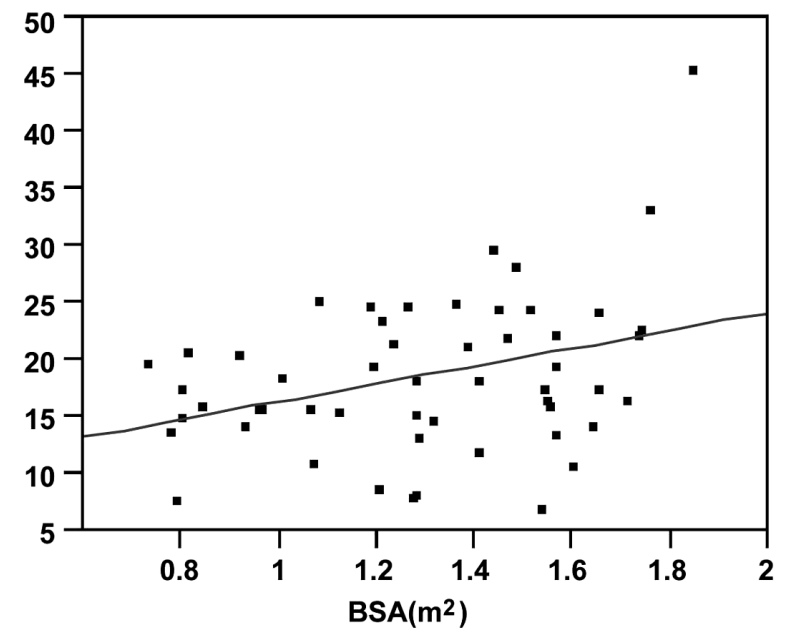

Fig 2. The relationship between coronary sinus (CS) size and the distance between the His bundle (HB) and CS (HB-CS) and body surface area (BSA). The upper panel shows the relationship between CS size and BSA. Note that there is a positive correlation between CS size and BSA. The lower panel shows the relationship between the $\mathrm{HB}-\mathrm{CS}$ distance and BSA. Note that there is a positive relationship between the $\mathrm{HB}-\mathrm{CS}$ distance and BSA.

and 2 AFL. An AP was located on the left side in 11 cases (3 left anterior, 2 left lateral, 1 left posterior lateral, 3 left posterior, and 2 left posterior septum) and on the right side in 13 cases ( 1 right anterior, 1 right anterior lateral, 3 right lateral, 3 right posterior lateral, 2 right posterior, and 3 right posterior septum). The AT location was in the left atrial appendage in 1 patient, left mitral valve ring in 1 patient, high right atrium in 1 patient, right lateral atrial wall in 1 patient, right atrial appendage in 1 patient, and CS in 2 patients. The VT location was in the right ventricular outflow tract in 2 patients. The common form of AFL was present in 2 patients.

\section{HB Recording Area}

The HB-L (17 $\pm 7 \mathrm{~mm})$ and HB-W $(11 \pm 5 \mathrm{~mm})$ for the HB recording area had no relationship with age, $\mathrm{BW}, \mathrm{BL}$ or BSA. The area of the HB recording area was $148 \pm 97 \mathrm{~mm}^{2}$ (Table 1). The shape of the HB recording area looked like a teardrop or oval (Fig 1).

\section{$C S$}

The CS-H (10 $\pm 3 \mathrm{~mm})$ had no relationship with age, BL, $\mathrm{BW}$ or BSA. The CS width (CS-W, $8 \pm 3 \mathrm{~mm})$ did not correlate with age, BW or BSA; however, it did correlate with BL $\left(\mathrm{p}=0.041, \mathrm{r}^{2}=0.081\right.$; Tables 1,2$)$. The CS area $\left(66 \pm 44 \mathrm{~mm}^{2}\right)$ correlated with BW, BL and BSA (Tables 1,2; Fig 2). The shape of the CS was oval or round.

\section{Distance From the HB to the CS}

The anatomical distance between the HB and CS (HB$\mathrm{CS} ; 18 \pm 7 \mathrm{~mm})$ was proportional with age $\left(\mathrm{p}=0.01, \mathrm{r}^{2}=\right.$ $0.127), B L\left(p=0.03, r^{2}=0.086\right), B W\left(p=0.01, r^{2}=0.138\right)$, and BSA $\left(\mathrm{p}=0.01, \mathrm{r}^{2}=0.118\right.$; Tables 1,2 ; Fig 2$)$.

Distance From the HB to the Slow Pathway Potential (SP)

$\mathrm{SP}$ was recorded in 28 cases. The anatomical distance between the HB and SP (HB-SP; $17 \pm 11 \mathrm{~mm}$ ) correlated with age $\left(\mathrm{p}=0.03, \mathrm{r}^{2}=0.177\right)$ and $\mathrm{BW}\left(\mathrm{p}=0.04, \mathrm{r}^{2}=0.152\right.$; Tables 1,2).

\section{Catheter Ablation}

Catheter ablation was successful in every case except in 1 patient with high right AT, who had only a few premature atrial contractions during the catheter ablation procedure. AT recurred in 4 patients. In 1 patient, AT recurred after AFL ablation. We made no further attempts at ablation because the AT focus was adjacent to the HB recording area. One of the patients with AT originating from the left appendage was ablated successfully during the second session. The other 2 patients were waiting for a second session of catheter ablation. AVNRT recurred in 1 patient; this patient was also waiting for a second session.

Ablation inside Koch's triangle was performed in 25 patients (ie, slow pathway ablation for AVNRT in 18, isthmus ablation for AFL in 2, CS ostium ablation for AT in 2, and posterior septal AP in 3). There were no complications, including atrioventricular block, in this study.

\section{Discussion}

The length of Koch's triangle is reported to be poorly correlated with BL, BW, and BSA in adults? The length is $18 \pm 3 \mathrm{~mm}$ in men and $17 \pm 3 \mathrm{~mm}$ in women. However, Goldberg et $\mathrm{al}^{3}$ reported that age, BW, BL and BSA are correlated with the dimensions of Koch's triangle in children. They reported that the different results between adult and children may be caused by concurrent cardiac tissue growth with somatic growth in children. Age, BW, BL and BSA are generally correlated; thus, the dimensions of Koch's triangle are, not surprisingly, predicted by each of 
these factors 3 Goldberg and colleagues' estimated length of Koch's triangle $=0.17+13.7 \times \mathrm{BSA}$ is somewhat shorter than what we determined in the present study. If BSA is $0.8 \mathrm{~m}^{2}$, then the length of Koch's triangle is $15.6 \mathrm{~mm}$ in our report and $11.1 \mathrm{~mm}$ based on Goldberg's report. Waki et al also reported that the dimension of Koch's triangle is age related. They did not determine the length of Koch's triangle but, based on the average of their data, specifically, it is $7.8 \mathrm{~mm}$ in patients less than 1 year of age, $12.2 \mathrm{~mm}$ in patients aged $1-12$ years, and $17.9 \mathrm{~mm}$ in patients aged $12-20$ years. These values are still smaller than those we obtained in the present study.

Several possible explanations for this difference are considered. First, Goldberg et al's study included very young children (age range, 1 day to 5.5 years; BSA range, $0.23-$ $0.82 \mathrm{~m}^{2}$ ) compared with the present study (age range, $4-19$ years; BSA range, $0.73-1.85 \mathrm{~m}^{2}$ ). Younger children may have a different size for Koch's triangle than older children. Second, the other 2 studies analyzed autopsy specimens whereas the present study used measurements from the beating heart. The beating heart may be stretched because it contains blood. Third, the distance in 3-D anatomical mapping differs from the open-heart 2-D distance. Finally, our length of Koch's triangle represents the distance between the $\mathrm{CS}$ and HB recording area. The HB recording area may exist a little more distal to the central fibrous body. However, when using the CARTO system, our distance may be a more useful standard in the clinical situation.

The HB is considered the distal portion of the compact atrioventricular node that penetrates inside the central fibrous body. In the human heart, because the distance from the atrium to the crest of the ventricular septum is short, the HB becomes short? The present study showed that the HB recording area is not a small focal point. Although it is possible to record far field HB potentials, we showed that the HB recording area looks like a teardrop or oval shape. The shape is larger in the proximal part and smaller in the distal part. This may indicate that the proximal part of the HB is wider than the distal part, or that the area of HB recording becomes narrower because the bundle penetrates into the central fibrous body.

From the present study, the size of the HB is not correlated with age and body size. To our knowledge, there are no previous studies relating HB size to body size in humans. The HB continues from the compact atrioventricular node and provides the connection to the left and the right bundle branches. We were unable to determine the actual size of the HB by endocardial recording techniques. The HB is thought to be smaller than a few millimeters in length; hence, the HB recording area, which used a 5-mm tip electrode catheter, may not directly reflect the size of the HB. Consequently, there was no correlation between the size and growth of the HB.

There were no major complications in this study after catheter ablation. The clinical usefulness of determining the length of Koch's triangle is unclear. However, to know the distance from the HB to the ablation point is useful in avoiding atrioventricular node injury, and information about the length of Koch's triangle may provide supportive information when applying radiofrequency energy inside Koch's triangle without needing to use the CARTO system in children. Due to the limited number of patients used in this study, further investigation is needed.

\section{References}

1. Koch W. Weiter Mitteilungen uber den Sinusknoten des Herzens. Verh Dtsch Ges Pathol 1909; 13: 85-92 (in German).

2. McGuire MA, Johnson DC, Robotin M, Richards DA, Uther JB, Ross DL. Dimensions of the triangle of Koch in humans. Am J Cardiol 1992; 70: 829-830.

3. Goldberg CS, Caplan MJ, Heidelberger KP, Dick M II. The dimensions of the triangle of Koch in children. Am J Cardiol 1999; 83: $117-120$.

4. Waki K, Kim JS, Becker AE. Morphology of the human atrioventricular node is age dependent: A feature of potential clinical significance. J Cardiovasc Electrophysiol 2000; 11: 1144-1151.

5. Jackman WM, Beckman KJ, McClelland JH, Wang X, Friday KJ, Roman CA, et al. Treatment of supraventricular tachycardia due to atrioventricular nodal re-entry, by radiofrequency catheter ablation of slow-pathway conduction. N Engl J Med 1992; 327: 313-318.

6. Haissaguerre M, Gaita F, Fischer B, Commenges D, Montserrat P, d'Ivernois $\mathrm{C}$, et al. Elimination of atrioventricular nodal re-entrant tachycardia using discrete slow potentials to guide application of radiofrequency energy. Circulation 1992; 85: 2162-2175.

7. Haissaguerre M, Dartigues JF, Warin JF, Le Metayer P, Montserrat $\mathrm{P}$, Salamon R. Electrogram patterns predictive of successful catheter ablation of accessory pathways: Value of unipolar recording mode. Circulation 1991; 84: 188-202.

8. Jackman WM, Wang XZ, Friday KJ, Roman CA, Moulton KP, Beckman KJ, et al. Catheter ablation of accessory atrioventricular pathways (Wolff-Parkinson-White syndrome) by radiofrequency current. N Engl J Med 1991; 324: 1605-1611.

9. Anderson RH, Ho SY, Becker AE. Anatomy of the human atrioventricular junctions revisited. Anat Rec 2000; 260: 81-91. 